\title{
Clinical and cost-effectiveness of physiotherapy interventions following total hip replacement: a systematic review and meta-analysis
}

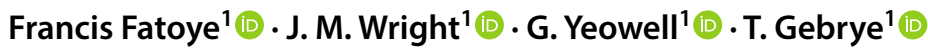

Received: 20 February 2020 / Accepted: 4 May 2020 / Published online: 25 May 2020

(c) The Author(s) 2020

\begin{abstract}
To examine the reported clinical and cost-effectiveness of physiotherapy interventions following total hip replacement (THR). A systematic review was completed according to the Preferred Reporting Items for Systematic Reviews and Meta-Analyses (PRISMA). MEDLINE, CINAHL, AMED, Scopus, DARE, HTA, and NHS EED databases were searched for studies on clinical and cost-effectiveness of physiotherapy in adults with THR published up to March 2020. Studies meeting the inclusion criteria were identified and key data were extracted. Risk of bias was assessed using the Cochrane Risk of Bias Tool and a Consolidated Health Economic Evaluation Reporting Standards (CHEERS). Data were summarised and combined using random-effect meta-analysis. A total of 1263 studies related to the aim of the review were identified, from which 20 studies met the inclusion criteria and were included in the review. These studies were conducted in Australia $(n=3)$, Brazil $(n=1)$, United States of America (USA) $(n=2)$, France $(n=2)$, Italy $(n=2)$, Germany $(n=3)$, Ireland $(n=1)$, Norway $(n=2)$, Canada $(n=1)$, Japan $(n=1)$, Denmark $(n=1)$, and United Kingdom (UK) $(n=1)$. The duration of follow-up of the included studies was ranged from 2 weeks to 12 months. Physiotherapy interventions were found to be clinically effective for functional performance, hip muscle strength, pain, and range of motion flexion. From the National Health Service perspective, an accelerated physiotherapy programme following THR was cost-effective. The findings of the review suggest that physiotherapy interventions were clinically effective for people with THR. However, questions remain on the pooled cost-effectiveness of physiotherapy interventions, and further research is required to examine this in patients with THR. Future studies are required to examine the cost-effectiveness of these interventions from patients, caregivers, and societal perspectives.

Registration Prospero (ID: CRD42018096524).
\end{abstract}

Keywords Cost-effectiveness $\cdot$ Physiotherapy $\cdot$ Total hip replacement $\cdot$ Systematic review

\section{Introduction}

Osteoarthritis (OA) is one of the major chronic diseases, and a primary cause of pain and disability among adults $[1,2]$. Hip and knee OA ranked as the 11th highest contributor to global disability and 38th highest in disability-adjusted life years (DALYs) [3]. Between 1990 and 2010, the global agestandardised prevalence of hip OA was 0.85\% [95\% uncertainty interval (UI) $0.74-1.02 \%$ ]. For people age $\geq 60$ years,

Francis Fatoye

f.fatoye@mmu.ac.uk

1 Department of Health Professions, Faculty of Health, Psychology, and Social Care, Manchester Metropolitan University, Brooks Building, 53 Bonsall Street, Manchester M15 6GX, UK the prevalence of radiographic hip OA (7\%) is less common than OA of the knee (37\%) [4]. The prevalence of OA of the hip is higher in females than males [3]. Due to the severe long-term pain and disability resulting from OA hip, its clinical and economic impact is substantial. People with OA of the hip have difficulty with functional activities as well as high levels of depression and anxiety [5, 6]. The total costs of OA in the United States of America (USA), France, United Kingdom (UK), Canada, and Australia accounted for between 1 and 2.5\% of the Gross National Product (GNP) for these countries [7]. In contrast, the cost of OA in Hong Kong accounted for $0.28 \%$ of the GNP which was between $£ 253$ million and $£ 308$ million [7]. From this, the annual direct and indirect costs per person ranged from $£ 384$ to $£ 883$ and $£ 261$ to £525, respectively [8]. 
Pharmaceutical management, non-pharmaceutical therapies, and surgical procedures are advocated by clinical guidelines for managing OA of the hip [9]. Total hip replacement (THR) is a common orthopaedic procedure for OA of the hip when conservative management fails [10]. Evidence showed that around 2.5 million (1.4 million women and 1.1 million men) Americans are living with a THR [11]. Current clinical guidelines recommend that non-pharmaceutical therapies including access to appropriate information to enhance understanding of the condition; activity and exercise; positive behavioural changes; manipulation and stretching; and transcutaneous electrical nerve simulation for patients following a THR for hip OA [12].

Previous systematic reviews have evaluated the effectiveness of physiotherapy interventions following THR; however, they reported conflicting findings $[13,14]$. Lowe et al. [13] indicated that physiotherapy exercise following THR has the potential to benefit patients. On the other hand, Wijnen et al. [14] identified that there was limited evidence to support the effectiveness of physiotherapy exercise following THR. Furthermore, there are no reviews that have been conducted on the cost-effectiveness of physiotherapy interventions following THR. Therefore, the purpose of this review was to investigate the clinical and cost-effectiveness of physiotherapy interventions following THR, which could be used to inform clinical practice and patient decision-making.

\section{Methods}

\section{Search protocol and registration}

This systematic review used the Preferred Reporting Items for Systematic Reviews and Meta-Analysis (PRISMA), a technique that addresses the eligibility, data sources, selection of studies, data extraction, and data analysis as a reporting guideline [15]. This review was registered on PROSPERO, with registration number, CRD: CRD42018096524.

\section{Data sources}

A search of literature for published and unpublished studies was conducted to MEDLINE, Cumulative Index to Nursing and Allied Health Literature (CINAHL), AMED, Scopus, Database of Abstracts of Reviews of Effects (DARE), Health Technology Assessment (HTA) database, and the National Health Service Economic Evaluation Database (NHS EED) in the last 2 decades. The search terms used were hip, replace*, "total hip replacement", arthroplasty, "total hip arthroplasty", "therapeutic exercise", training, "functional training", "home physical training", "joint mobilization", exercise, physical therapist, therap*, treatment, medicine, muscle*, quadriceps*, strength, function, kinesiotherap*, rehabilitation, physiotherapy, "exercise therapy", "physical therapy", effectiveness, "clinical effectiveness", cost, value, money, expenditure, QALY, HRQoL, "healthcare costs", economics, "cost-effectiveness analysis", "cost-utility analysis", and "cost-benefit analysis". These search terms were combined using conjunctions such as "AND" and "OR".

\section{Search strategy}

The Population, Intervention, Comparison, Outcome (PICO) framework was utilized in the development of the search strategy with search terms and limits relating to population of interest and intervention. The inclusion criteria were studies that: included patients (mean age $\geq 18$ years) following THR for hip OA; assessed the clinical or cost-effectiveness of different forms of physiotherapy compared to other forms of physiotherapy or no intervention; reporting results of randomized-controlled and retrospective/prospective trials. In this review, physiotherapy interventions covered a range of techniques including massage, passive stretching, functional rehabilitation, interdisciplinary rehabilitation, exercise, physical training, acupuncture, spinal manipulation, advice, yoga, cognitive behavioural therapy, and martial arts. The economic evaluation (cost-effectiveness analysis, cost-benefit analysis, and cost-utility analysis) carried out alongside randomized-controlled trials and retrospective cohort study were included.

The outcomes of interest in this review included: pain, function, muscle strength, clinical and motor performance, activities of daily living, and health-related quality of life. To be included for the economic evaluation, studies had to relate the costs of the interventions to the effects of the interventions. Systematic reviews, narrative literature reviews, studies of non-English language, and conference papers were excluded. Further exclusion criteria were abstract unavailable, studies not yet fully completed, and studies carried out with THR patients mean aged $<18$ years.

Duplicates were removed electronically and manually. Two independent researchers (TG and FF) were involved in screening the title and abstract of each study. Full-text articles were obtained and were excluded if they did not meet the inclusion criteria. Any disagreement in study selection was resolved through discussion and consultation with other members of the team (GY and JMW) where necessary.

\section{Data extraction and risk of bias assessment}

One of the researchers extracted data (TG) and the three members of the team cross-checked the extracted data (FF, GY, and JMW). The following data were extracted: author and date of the study, the location/country, type of participant, and the number of participants involved in the study. 
The mean age, percentage of male and female participants who received the interventions and the control arm, and the type and the duration of the physiotherapy interventions were also extracted from each study. Furthermore, data regarding outcome measures, including the primary and secondary health outcomes, resource use and cost, and the cost-effectiveness ratio (ICER) were extracted.

Risk of bias for studies that met the inclusion criteria for the clinical effectiveness was assessed using the criteria of the Cochrane Risk of Bias Tool [16]. The Cochrane Collaboration's tool aims to make the process clearer and more accurate, and it covers six domains of bias such as selection bias, performance bias, detection bias, attrition bias, reporting bias, and other bias. Studies were considered high risk of bias when one or more of the key domains had unclear or high risk of bias [16].

The Consolidated Health Economic Evaluation Reporting Standards (CHEERS) statement was also used as a reporting guideline for the included cost-effectiveness studies [17]. Twenty-four items were addressed in six categories, which include title and abstract, introduction, methods, results, discussion, and others. Cost-effectiveness studies were rated positive $(\sqrt{ })$ if they reported in full, and negative $(x)$ if they did not fulfil the listed criteria in the CHEERS statement. For those studies that have partial or inconclusive information, they were labelled as partial $(P)$. A total score of 1 was assigned if they fulfilled the requirement of reporting for that Item completely, 0 for not reporting and 0.5 for partial reporting. The maximum score for an article that reported completely all information was 24 .

\section{Data analysis}

A descriptive synthesis and meta-analysis of the extracted data is presented. This study considered a weighting procedure for the clinical effectiveness of physiotherapy interventions as well as its cost-effectiveness of the included studies only when the procedure for combining data from multiple studies was satisfied. The continuous outcomes measures were expressed as a weighted mean difference with $95 \%$ confidence intervals. To summarise the findings across the studies, a statistical significance of $p<0.05$ was set. Due to the statistical evidence of heterogeneity across the studies, a random-effects model was chosen [15].

\section{Results}

From the literature search, 1263 potentially relevant studies were identified. Of these, 181 duplicates were removed. The title and abstract of the remaining 1082 studies were screened for eligibility. The full texts of 44 remaining studies were reviewed. Overall, 20 studies were eligible and included in this review. A summary is provided in the systematic review flow diagram (Fig. 1).

\section{Study characteristics}

Eighteen studies assessed the clinical effectiveness of physiotherapy interventions and two studies examined costeffectiveness of the interventions using information from 1400 and 108 patients following THR, respectively. The duration of follow-up of patients in the included studies ranged from 2 weeks to 12 months. The mean age of the participants in the intervention and control groups ranged from 46.93-68.6 years and 55.5-68.58 years, respectively. The geographical locations of these studies were: Australia $(n=3)$, Brazil $(n=1)$, USA $(n=2)$, France $(n=2)$, Italy $(n=2)$, Germany $(n=3)$, Ireland $(n=1)$, Norway $(n=2)$, Canada $(n=1)$, Japan $(n=1)$, Denmark $(n=1)$, and UK $(n=1)$ (Table 1).

\section{Risk of bias}

The assessment of risk of bias of the included clinical effectiveness studies is presented in Table 2. All the included studies have unclear or high risk of bias within at least one domain, and thus, no studies have achieved a low risk of bias. Except two studies that were assigned high risk of bias [18] and unclear risk of bias [19] for reporting bias, most of the included studies achieved low risk of bias for the reporting and other bias. Thirteen and 16 out of 18 studies had high risk of bias for treatment allocation and blinding of participants of intervention. Sixteen out of eighteen studies had low risk of bias and two studies [20,21] had unclear risk of bias for blinding outcome assessment. Five of eighteen studies were assigned unclear attrition bias, and the remaining studies had low risk of bias.

In relation to the two included cost-effectiveness studies [22, 23], the CHEERS scores suggest that the methodological quality of the included studies had adequate quality (Table 4).

\section{Effectiveness of physiotherapy interventions}

The effectiveness of physiotherapy interventions was assessed in the included studies.

\section{Acute hospital length of stay}

Haas et al. [19] investigated the effect of an acute weekend physiotherapy service compared to no physiotherapy service following THR. Weekend physiotherapy service was associated with significantly increased odds of discharge directly home [odds ratio 3.151 (1.039-9.555)] and improved mobility [coefficient $4.301(1.500-7.101)]$. However, patients in 


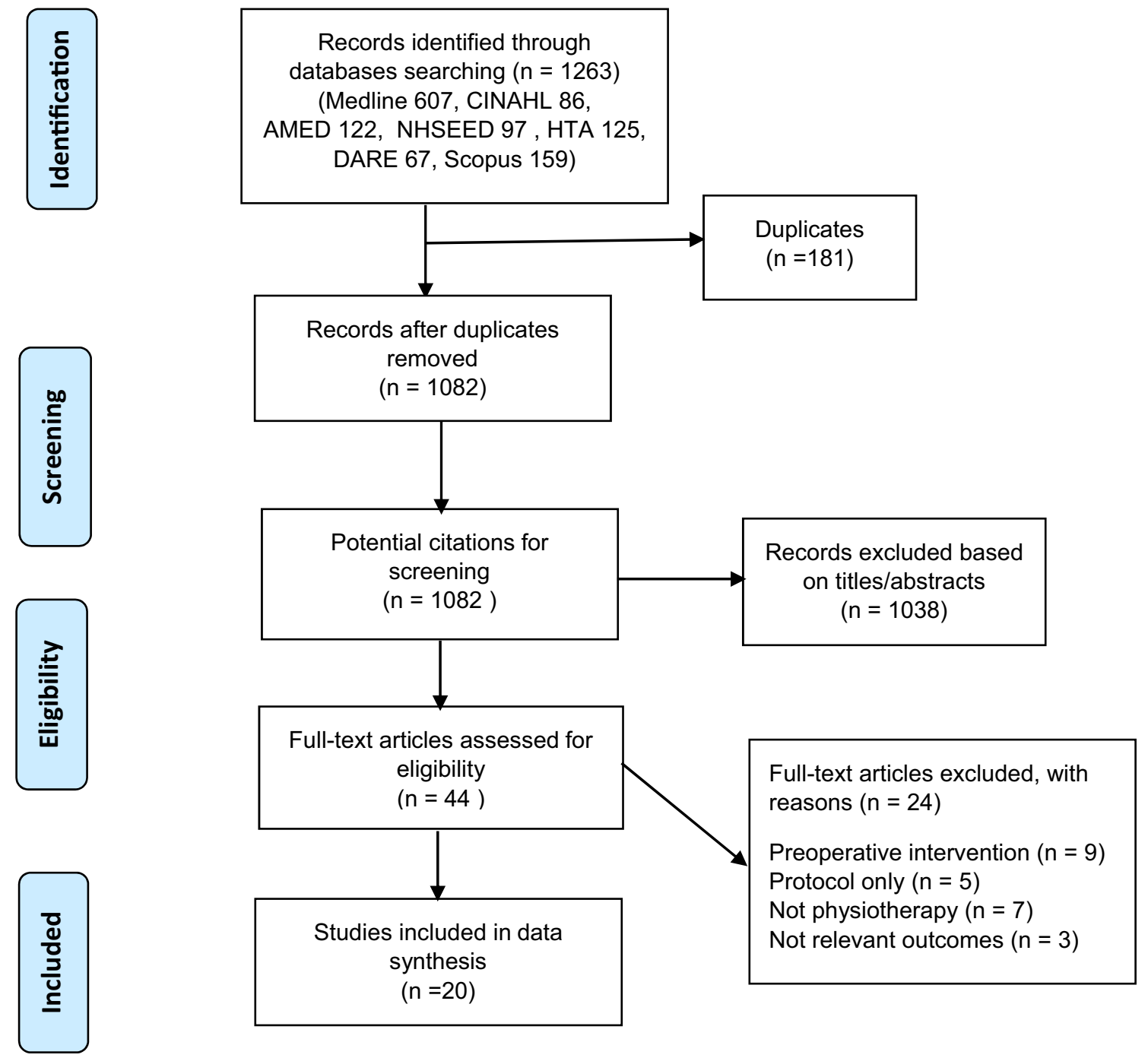

Fig. 1 Systematic review flow diagram

the intervention group perceived hospitalisation as less helpful and acute length of stay was longer compared to patients without physiotherapy services at the weekend. Overall, weekend physiotherapy service was beneficial on discharge destination and patient mobility.

\section{Health-related quality of life}

Three studies reported the impact of physiotherapy interventions on health-related quality of life (HRQoL) [21, 24, 25]. The Euroqol visual analogue scale [21, 24] and a self-administered HRQoL questionnaire [25] were used to assess the quality of life of THR patients. The comparative advantage of a targeted home- and centre-based exercise programme over unsupervised home-based exercise group were examined in patients following THR [25]. Patients who received the targeted home- and centre-based exercise programme achieved significant improvements $(p<0.05)$ in HRQoL. On the other hand, no clinically significant difference was observed between patients following THR in the groups who received inpatient and sports rehabilitation compared with control on HRQoL at 1 year [21, 24].

\section{Function}

The effects of physiotherapy interventions on functional performance in patients following THR were assessed in six studies [20, 26-30]. The findings of these studies demonstrated that hydrotherapy, home exercise programme, physiotherapy-led functional exercise program, a 6-week arm exercise programme, an arm-interval exercise program, in-hospital program based on task-oriented exercises, and a targeted home and centre exercise programme were effective in improving the functional performance of 


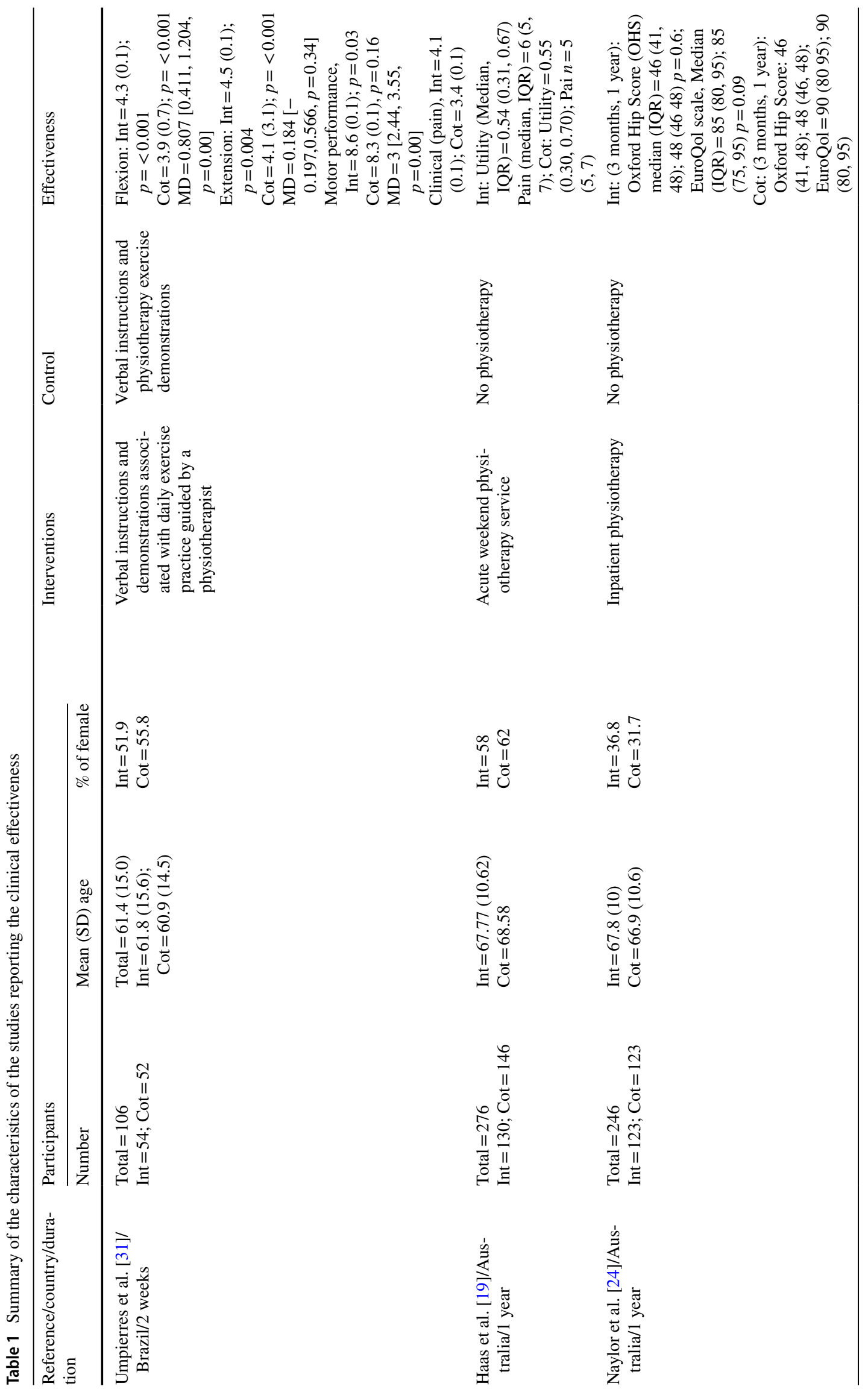




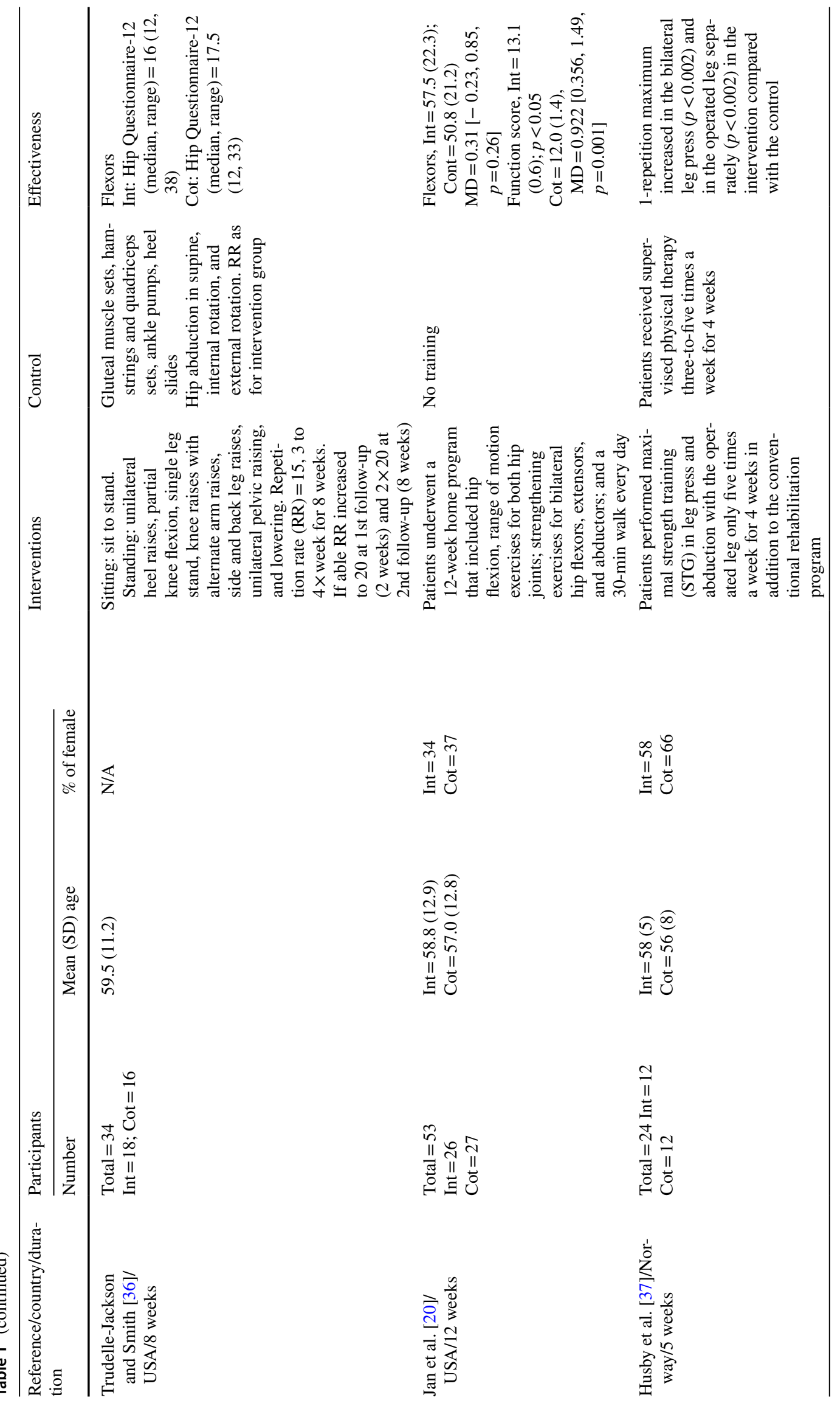




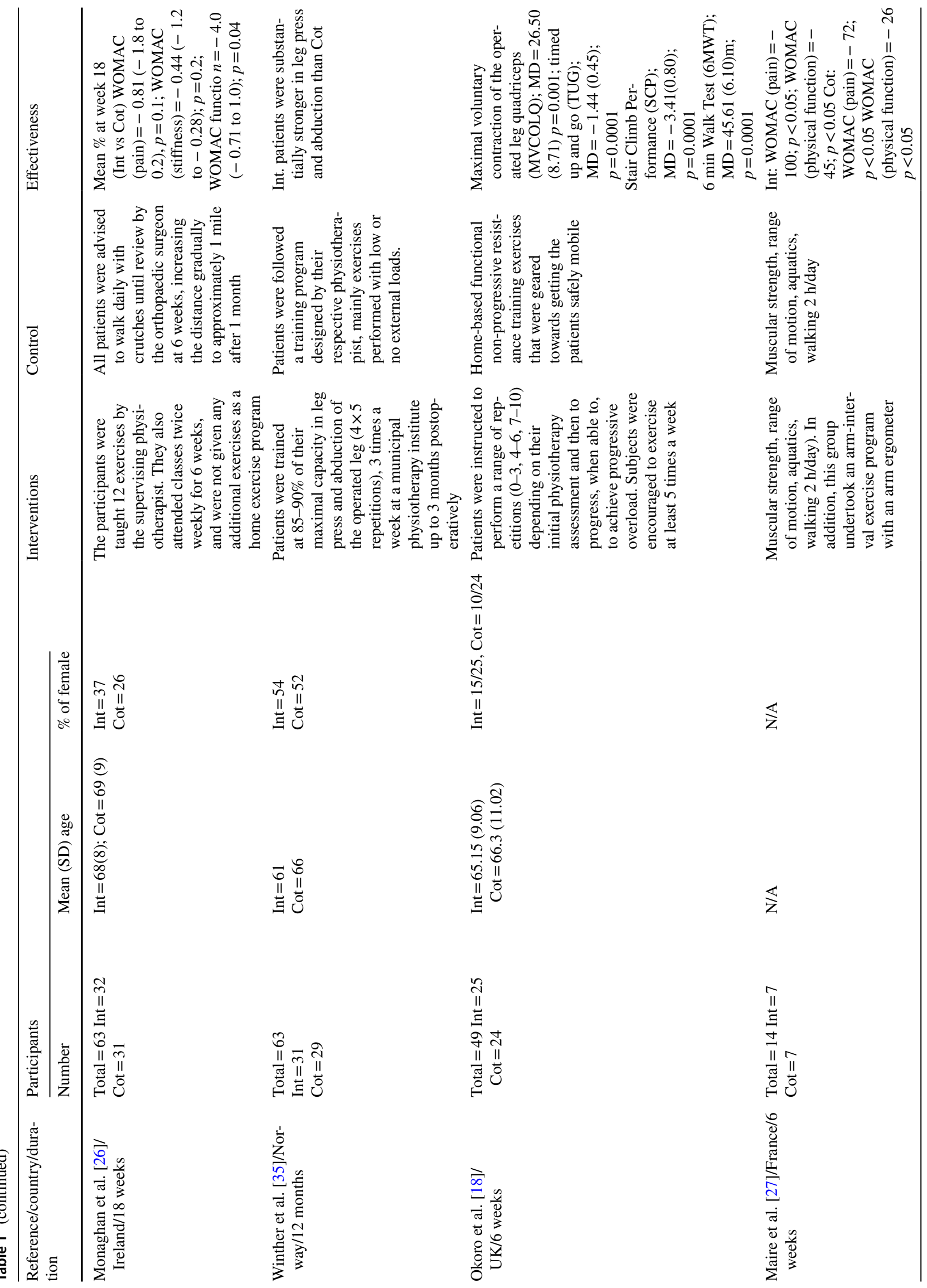




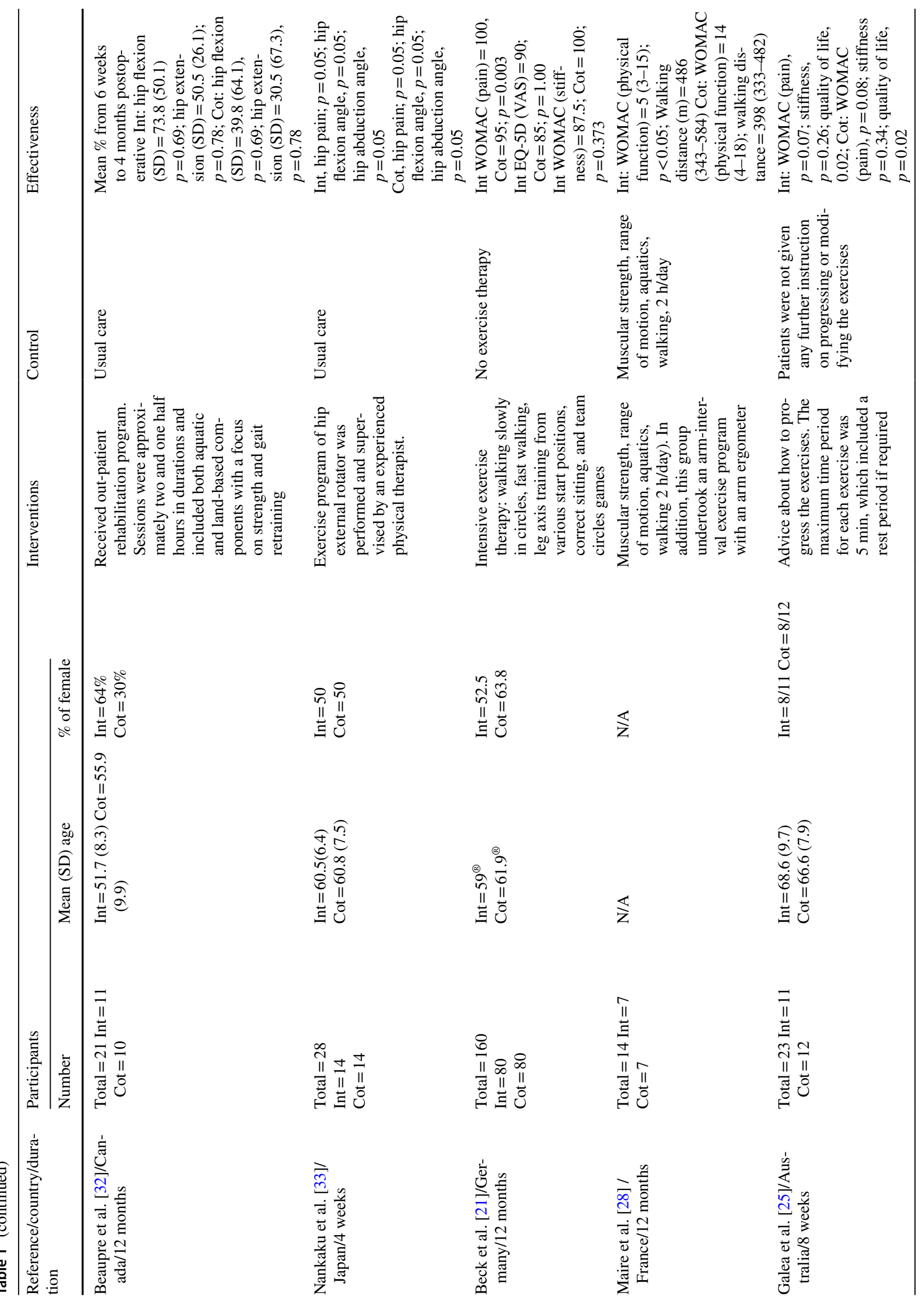




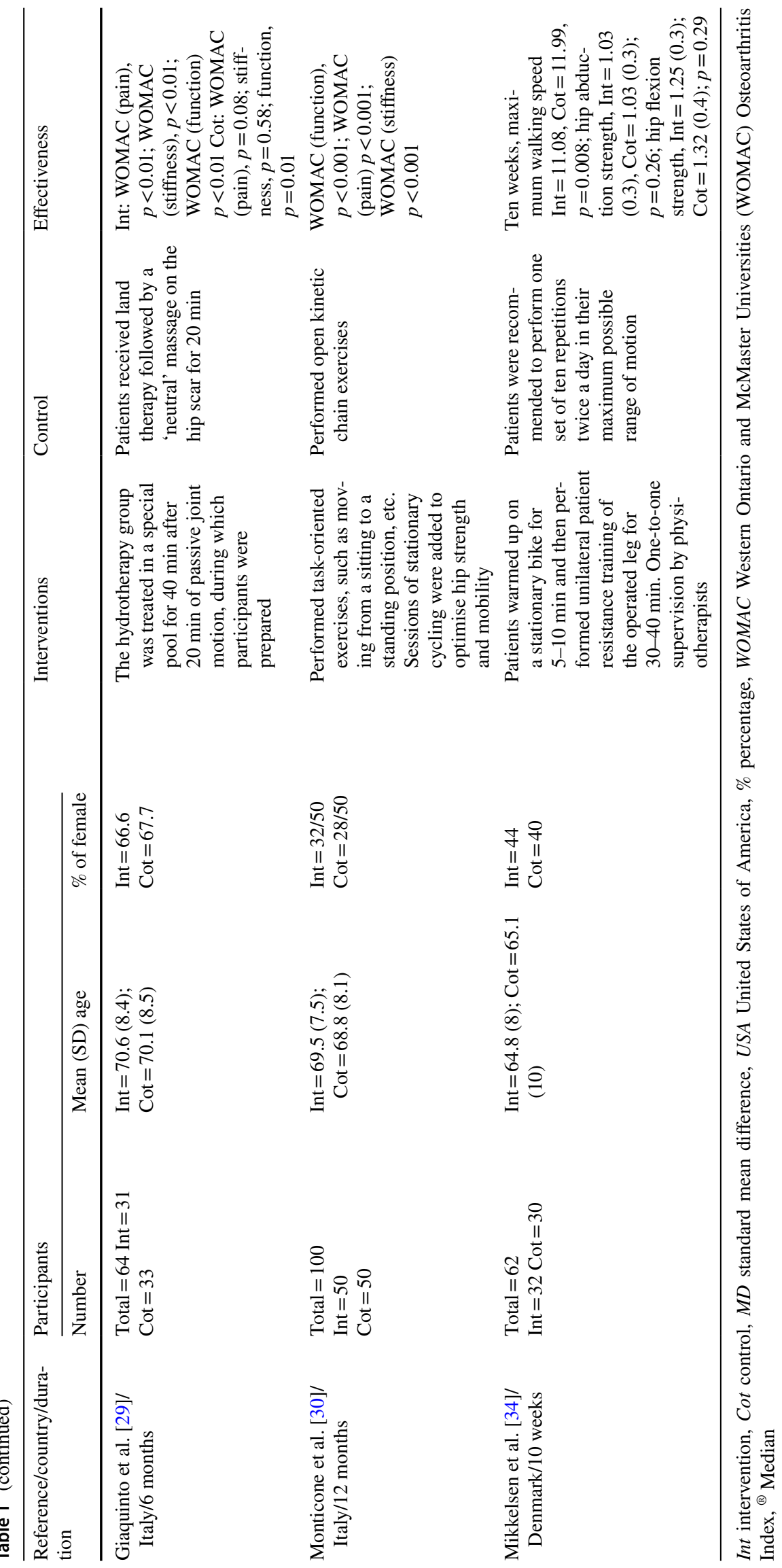


Table 2 Summary of risk of bias assessment

\begin{tabular}{|c|c|c|c|c|c|c|c|}
\hline & $\begin{array}{l}\text { Random } \\
\text { sequence gen- } \\
\text { eration (selection } \\
\text { bias) }\end{array}$ & $\begin{array}{l}\text { Allocation } \\
\text { concealment } \\
\text { (selection bias) }\end{array}$ & $\begin{array}{l}\text { Blinding of } \\
\text { participants and } \\
\text { personnel (per- } \\
\text { formance bias) }\end{array}$ & $\begin{array}{l}\text { Blinding of out- } \\
\text { come assessment } \\
\text { (detection bias) }\end{array}$ & $\begin{array}{l}\text { Incomplete } \\
\text { outcome data } \\
\text { (attrition bias) }\end{array}$ & $\begin{array}{l}\text { Selective report- } \\
\text { ing (reporting } \\
\text { bias) }\end{array}$ & Other bias \\
\hline $\begin{array}{l}\text { Umpierres et al. } \\
\text { [31] }\end{array}$ & +1 & +1 & -1 & +1 & +1 & +1 & +1 \\
\hline Haas et al. [19] & -1 & -1 & -1 & +1 & +1 & $?$ & +1 \\
\hline Naylor et al. [24] & -1 & -1 & -1 & +1 & +1 & +1 & +1 \\
\hline $\begin{array}{c}\text { Trudelle-Jackson } \\
\text { and Smith [36] }\end{array}$ & $?$ & -1 & 1 & +1 & $?$ & +1 & +1 \\
\hline Jan et al. [20] & -1 & -1 & -1 & $?$ & +1 & +1 & +1 \\
\hline Husby et al. [37] & +1 & -1 & -1 & +1 & $?$ & +1 & +1 \\
\hline $\begin{array}{l}\text { Monaghan et al. } \\
\text { [26] }\end{array}$ & +1 & +1 & -1 & +1 & +1 & +1 & +1 \\
\hline Okoro et al. [18] & +1 & +1 & - & +1 & $?$ & -1 & +1 \\
\hline Maire et al. [27] & $?$ & -1 & -1 & +1 & +1 & +1 & +1 \\
\hline $\begin{array}{l}\text { Beaupre et al. } \\
\text { [32] }\end{array}$ & +1 & -1 & 1 & +1 & +1 & +1 & +1 \\
\hline $\begin{array}{l}\text { Nankaku et al. } \\
\text { [33] }\end{array}$ & +1 & -1 & -1 & +1 & +1 & +1 & +1 \\
\hline Maire et al. [28] & +1 & -1 & -1 & +1 & +1 & +1 & +1 \\
\hline Galea et al. [25] & +1 & -1 & -1 & +1 & +1 & +1 & +1 \\
\hline $\begin{array}{l}\text { Giaquinto et al. } \\
\text { [29] }\end{array}$ & $?$ & -1 & -1 & +1 & $?$ & +1 & +1 \\
\hline $\begin{array}{l}\text { Monticone et al. } \\
{[30]}\end{array}$ & +1 & +1 & -1 & +1 & +1 & +1 & +1 \\
\hline $\begin{array}{l}\text { Mikkelsen et al. } \\
\text { [34] }\end{array}$ & +1 & +1 & -1 & +1 & +1 & +1 & +1 \\
\hline $\begin{array}{l}\text { Winther et al. } \\
\text { [35] }\end{array}$ & $?$ & -1 & -1 & $?$ & +1 & +1 & +1 \\
\hline Beck et al. [21] & $?$ & -1 & -1 & +1 & $?$ & +1 & +1 \\
\hline
\end{tabular}

+1 , low risks of bias, -1 , high risk of bias, ?, unclear risk of bias

patients following THR. One of the studies [20] used Harris Hip Score to measure function, whereas the remaining five studies [26-30] used Western Ontario and McMaster Universities (WOMAC) Osteoarthritis Index.

\section{Muscle strength}

Six studies investigated the effects of physiotherapy interventions on hip flexors muscle strength following THR [26, 31-35]. Compared to patients assigned into the control, improved hip muscle strength was observed in patients following THR who received home exercise programme, postoperative exercise programme, exercise programme focussing on hip external rotator muscle, supervised progressive resistance training, rehabilitation and muscle strength training.

\section{Range of movement}

Range of motion flexion data suitable for meta-analysis were available from two studies that compared physiotherapy and no physiotherapy interventions [20,31]. As it is demonstrated in Table 3, there was evidence that physiotherapy interventions significantly improved range of motion flexion with a standard difference in means 0.634 (95\% CI 0.170 , $1.098, p=0.007)$.

\section{Pain}

The effectiveness of physiotherapy on hip pain following THR was examined in seven studies conducted across different countries [20, 26, 27, 29-31, 33]. The findings of five of the studies [27, 29-31,33] showed that hip pain was significantly improved for those patients following THR in the 
Table 3 Forest plot of the mean difference I hip flexion for total hip replacement between physiotherapy and without physiotherapy

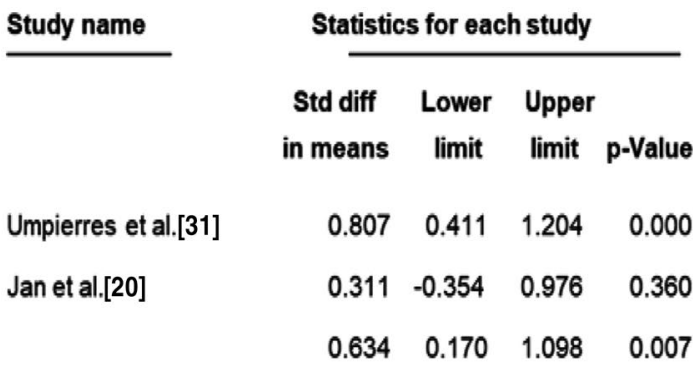

Favours Cot

\section{Std diff in means and $95 \% \mathrm{Cl}$}

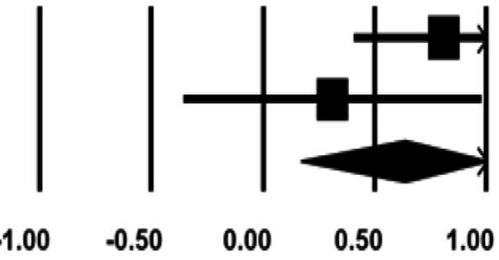

Favours Tx

Cot control, $T x$ treatment, $C I$ confidence interval

intervention group compared to control. Whereas two studies $[26,31]$ reported that patients following THR received home- and centre-based exercise and physiotherapy supervised functional exercise programme showed no significant improvement in hip pain.

\section{Clinical and motor performance}

One study [31] reported the effect of physiotherapy interventions on clinical and motor performance. The patients $(n=54)$ received rehabilitation assisted by the multidisciplinary hip group with the presence of physiotherapy professionals. After the 15th postoperative day after discharge, those in the intervention groups showed greater improvements in clinical (gait, pain, and mobility) and motor performance (gait and pain) $(p<0.001)$ compared with those patients supported without physiotherapy professionals. Those in the intervention group have also showed significantly greater improvements in muscle strength force (flexion, $p<0.001$; extension, $p<0.001$; abduction, $p=0.003$; internal rotation, $p<0.001$; external rotation, $p<0.001$ ) compared to the non-intervention group.

\section{Cost-effectiveness of physiotherapy interventions}

Two of the included studies that compared accelerated physiotherapy with standard physiotherapy [22] and in-patient rehabilitation with out-patient physiotherapy [23] have conducted economic evaluation in patients of OA following THR (Table 4). The design of the studies was a cost-utility analysis alongside randomized-controlled trial [22] and retrospective cohort study [23]. From the National Health Service (NHS) and healthcare insurer perspective, a £504 per patient [22] and $€ 9,126.00$ [23] costs were estimated for the accelerated physiotherapy and in-patient rehabilitation, respectively. The incremental cost-effectiveness ratio estimate by Fusco et al. [22] and Krummenauer et al. [23] was $£ 1,538 / \mathrm{QALY}$ and $-€ 841 / \mathrm{QALY}$ gained, respectively. Overall, inpatient rehabilitation [23] was not cost-effective, whereas accelerated physiotherapy was associated with cost savings to the NHS of $£ 200$ per patient and additional 0.13 QALY [22].

\section{Discussion}

This is the first systematic review and meta-analysis on clinical and cost-effectiveness of physiotherapy interventions following THR. The search strategy identified 20 clinical and cost-effectiveness studies on physiotherapy interventions from Australia, Brazil, USA, France, Italy, Germany, Ireland, Norway, Canada, Japan, Denmark, and United Kingdom. The risk of bias in these studies was assessed using the Cochrane Risk of Bias Tool. All of the 18 studies included for the clinical effectiveness of physiotherapy interventions in the review had unclear or high risk of bias. The methodological quality of the two cost-effectiveness studies was assessed as adequate.

In line with the findings a systematic review by Lowe et al. [13] on clinical effectiveness of physiotherapy exercise following hip arthroplasty for osteoarthritis, the present study confirmed that physiotherapy interventions improved physical function, health-related quality of life, mobility, and muscle strength. In addition, the findings of our review showed that physiotherapy interventions improved self-perceived function, postural stability, fast-walking speed, stair climbing, and discharge destination following THR. On the other hand, physiotherapy interventions did not reduce hospital length of stay, fear of falling, hip pain, and function. Furthermore, compared to out-patient physiotherapy interventions, inpatient physiotherapy interventions following THR did not show a significantly superior cost-effectiveness from a healthcare insurer perspective. 
Table 4 Summary of the characteristics of the studies reporting the clinical outcomes and cost-effectiveness for patients of THR

\begin{tabular}{|c|c|c|c|c|c|c|c|}
\hline $\begin{array}{l}\text { Study/location/ } \\
\text { study design/time- } \\
\text { horizon }\end{array}$ & Population & Intervention & Control & $\begin{array}{l}\text { Outcomes/meas- } \\
\text { urement used }\end{array}$ & Cost/perspective & Results (Int vs Cot) & $/ 24^{\varphi}$ \\
\hline $\begin{array}{l}\text { Fusco et al. } \\
\text { [22]; UK/cost- } \\
\text { utility analy- } \\
\text { sis/12 months }\end{array}$ & $\# 80$ & $\begin{array}{l}\text { Accelerated physi- } \\
\text { otherapy re-edu- } \\
\text { cation to increase } \\
\text { walking distance } \\
\text { and direction and } \\
\text { reduce reliance } \\
\text { on aids }\end{array}$ & $\begin{array}{l}\text { Standard physi- } \\
\text { otherapy }\end{array}$ & EuroQol EQ-5D & $\begin{array}{l}\text { Direct cost/ } \\
\text { National Health } \\
\text { Service }\end{array}$ & $\begin{array}{l}\text { Cost } \\
\text { I } n=£ 504 \text { per } \\
\text { patient } \\
\text { Cot }=£ 705 \text { per } \\
\text { patient } \\
\text { Effectiveness } \\
\text { Int }=0.91(0.03) \\
\text { Cot }=0.73(0.05) \\
\text { Cost-effectiveness } \\
\text { Int. was cost-effec- } \\
\text { tive than Cot }\end{array}$ & 22 \\
\hline $\begin{array}{l}\text { Krummenauer } \\
\text { et al. [23] } \\
\text { Germany/cost- } \\
\text { effectiveness } \\
\text { analysis/6 months }\end{array}$ & \#28 & $\begin{array}{l}\text { In-patient physi- } \\
\text { otherapy }\end{array}$ & $\begin{array}{l}\text { Out-patient physi- } \\
\text { otherapy }\end{array}$ & $\begin{array}{l}\text { WOMAC score } \\
(\%), \text { utility, qual- } \\
\text { ity adjusted life } \\
\text { years }\end{array}$ & $\begin{array}{l}\text { Direct costs/health- } \\
\text { care insurer }\end{array}$ & $\begin{array}{l}\text { Cost } \\
\text { Int }=€ 9126.00 ; \\
\text { Cot }=€ 8706.00 \\
\text { Effectiveness } \\
\text { Int }=38 \% \text { before, } \\
\text { and } 87 \% \text { after } \\
\text { surgery (WOMC } \\
\text { score) } \\
\text { Cot }=41 \% \text { before, } \\
\text { and } 88 \% \text { after } \\
\text { surgery } \\
\text { Cost-effectiveness } \\
\text { Cost/effect }=€ 420 \\
{[198,475] / 0.77} \\
{[95 \% \text { CI }-2.13,} \\
3.18] \text { QALYs } \\
=-€ 841 / \text { QALY } \\
(p=0.791) \\
\text { Inpatient reha- } \\
\text { bilitation was } \\
\text { not cost-effective } \\
\text { compared to out- } \\
\text { patient rehabilita- } \\
\text { tion }\end{array}$ & 20 \\
\hline
\end{tabular}

Int intervention, Cot control, WOMAC Western Ontario and McMaster Universities (WOMAC) Osteoarthritis Index

${ }^{\varphi}$ CHERS Quality score

The results of the meta-analysis of two studies [20, 31] also showed that physiotherapy intervention was beneficial compared to a control, which contradicts the findings of Lowe and colleagues [13]. Their review which focussed specifically on an outcome measure of range of motion such as flexion, extension defect, and abduction that combined data from four studies showed that there were no statistically significant differences between groups for hip joint range of motion. One possible reason for the contradiction may be the characteristics of the physiotherapy interventions such as exercise, duration of follow-up, and the outcome measures used in the individual studies.

We have adopted a robust search strategy to locate and identify all potential studies that investigated the effectiveness and cost-effectiveness of physiotherapy interventions including exercise, massage, taping, kinesiology, rehabilitation, joint mobilisation, and sport. Four independent reviewers have participated in the review process, and it has been possible to include all relevant literature in this study. Due to the fact that public health practitioners and policymakers are utilizing innovative and up-todate physiotherapy guidelines, this review has focused on studies carried out in the last 2 decades. Given the small number of studies included for this review, the clinical and cost-effectiveness of physiotherapy interventions should be interpreted with caution. The present review may have been affected by language bias. Consequently, a small number of studies published in languages other than English might have been excluded and it is difficult to generalize the clinical and cost-effectiveness of physiotherapy interventions based on the findings of this review. 


\section{Conclusion}

This review indicates that following THR, patients with OA of the hip showed significant improvement in physical function, health-related quality of life, mobility, and muscle strength with physiotherapy interventions in a short term. On the other hand, physiotherapy interventions were not effective in terms of hospital length of stay, acute length of stay, fear of falling, and hip pain and function for patients following THR. In relation to the findings of the cost-effectiveness of physiotherapy interventions in this review, it is difficult to reach a conclusion as they were based on a small number of studies. In addition, outcome measures used in future studies need to include those which measure (or reflect) the wider social determinants of health; for example, the perspectives of patients, their caregivers, and other societal perspectives.

Author contributions FF, JMW, GY, and TG had conceived, designed, analysed the data, and interpreted the results of the work. FF, JMW, GY, and TG wrote and critically revised the paper. All authors approved the final version of this manuscript.

Funding This research received no specific grant from any funding agency in the public, commercial, or not-for-profit sectors.

\section{Compliance with ethical standards}

Conflict of interest None of the authors have any competing interests to declare.

Ethical approval The study is a systematic review. For this study, ethical approval was not required.

Open Access This article is licensed under a Creative Commons Attribution 4.0 International License, which permits use, sharing, adaptation, distribution and reproduction in any medium or format, as long as you give appropriate credit to the original author(s) and the source, provide a link to the Creative Commons licence, and indicate if changes were made. The images or other third party material in this article are included in the article's Creative Commons licence, unless indicated otherwise in a credit line to the material. If material is not included in the article's Creative Commons licence and your intended use is not permitted by statutory regulation or exceeds the permitted use, you will need to obtain permission directly from the copyright holder. To view a copy of this licence, visit http://creativecommons.org/licenses/by/4.0/.

\section{References}

1. Song J, Chang RW, Dunlop DD (2006) Population impact of arthritis on disability in older adults. Arthritis Care Res Off J Am Coll Rheumatol 55(2):248-255

2. Johnson VL, Hunter DJ (2014) The epidemiology of osteoarthritis. Best Pract Res Clin Rheumatol 28(1):5-15

3. Cross M, Smith E, Hoy D, Nolte S, Ackerman I, Fransen M, Laslett LL (2014) The global burden of hip and knee osteoarthritis: estimates from the global burden of disease 2010 study. Ann Rheum Dis 73(7):1323-1330

4. Zhang Y, Jordan JM (2010) Epidemiology of osteoarthritis. Clin Geriatr Med 26(3):355-369

5. Guccione AA, Felson DT, Anderson JJ, Anthony JM, Zhang Y, Wilson PW, Kannel WB (1994) The effects of specific medical conditions on the functional limitations of elders in the Framingham Study. Am J Public Health 84(3):351-358

6. Murphy LB, Sacks JJ, Brady TJ, Hootman JM, Chapman DP (2012) Anxiety and depression among US adults with arthritis: prevalence and correlates. Arthritis Care Res 64(7):968-976

7. March LM, Bachmeier CJ (1998) Economics of osteoarthritis: a global perspective. Occup Health Ind Med 3(38):154

8. Woo J, Lau E, Lau CS, Lee P, Zhang J, Kwok T, Lam D (2003) Socioeconomic impact of osteoarthritis in Hong Kong: utilization of health and social services, and direct and indirect costs. Arthritis Care Res Off J Am Coll Rheumatol 49(4):526-534

9. Zhang W, Doherty M, Arden N, Bannwarth B, Bijlsma J, Gunther KP, Leeb B (2005) EULAR evidence based recommendations for the management of hip osteoarthritis: report of a task force of the EULAR Standing Committee for International Clinical Studies Including Therapeutics (ESCISIT). Ann Rheum Dis 64(5):669-681

10. National Collaborating Centre for Chronic Conditions (Great Britain), \& National Institute for Clinical Excellence (Great Britain) (2008) Osteoarthritis: national clinical guidelines for care and management in adults. Royal College of Physicians

11. Kremers HM, Larson DR, Crowson CS, Kremers WK, Washington RE, Steiner CA, Berry DJ (2015) Prevalence of total hip and knee replacement in the United States. J Bone Jt Surg (American volume) 97(17):1386

12. Conaghan PG, Dickson J, Grant RL (2008) Care and management of osteoarthritis in adults: summary of NICE guidance. BMJ 336(7642):502-503

13. Lowe CJM, Barker KL, Dewey ME, Sackley CM (2009) Effectiveness of physiotherapy exercise following hip arthroplasty for osteoarthritis: a systematic review of clinical trials. BMC Musculoskelet Disord 10(1):98

14. Wijnen A, Bouma SE, Seeber GH, van der Woude LH, Bulstra SK, Lazovic D et al (2018) The therapeutic validity and effectiveness of physiotherapeutic exercise following total hip arthroplasty for osteoarthritis: a systematic review. PloS One 13(3): $1-21$

15. Shamseer L, Moher D, Clarke M, Ghersi D, Liberati A, Petticrew $M$ et al (2015) Preferred reporting items for systematic review and meta-analysis protocols (PRISMA-P) 2015: elaboration and explanation. BMJ 349:1-25

16. Higgins JP, Altman DG, Gøtzsche PC, Jüni P, Moher D, Oxman AD, Sterne JA (2011) The Cochrane Collaboration's tool for assessing risk of bias in randomised trials. BMJ 343:d5928

17. Husereau D, Drummond M, Petrou S, Carswell C, Moher D, Greenberg D, Loder E (2013) Consolidated health economic evaluation reporting standards (CHEERS) statement. Int J Technol Assess Health Care 29(2):117-122

18. Okoro T, Whitaker R, Gardner A, Maddison P, Andrew JG et al (2016) Does an early home-based progressive resistance training program improve function following total hip replacement? Results of a randomized controlled study. BMC Musculoskelet Disord 17(1):1-9

19. Haas R, O’Brien L, Bowles KA, Haines T (2018) Effectiveness of a weekend physiotherapy service on short-term outcomes following hip and knee joint replacement surgery: a quasiexperimental study. Clin Rehabil 32(11):1493-1508

20. Jan MH, Hung JY, Lin H, Wang SF, Liu TK, Tang PF (2004) Effects of a home program on strength, walking speed, and 
function after total hip replacement. Arch Phys Med Rehabil 85(12):1943-1951

21. Beck H, Beyer F, Gering F, Günther KP, Lützner C, Walther A, Stiehler M (2019) Sports therapy interventions following total hip replacement: a randomized controlled trial. Deutsches Ärzteblatt International 116(1-2):1

22. Fusco F, Campbell H, Barker K (2019) Rehabilitation after resurfacing hip arthroplasty: cost-utility analysis alongside a randomized controlled trial. Clin Rehabil 33(6):1003-1014

23. Krummenauer F, Gunther K, Witzleb W (2008) The incremental cost efectiveness of in-patient versus out-patient rehabilitation after total hip arthroplasty-results of a pilot investigation. Eur J Med Res 13(6):267

24. Naylor JM, Hart A, Mittal R, Harris IA, Xuan W (2018) The effectiveness of inpatient rehabilitation after uncomplicated total hip arthroplasty: a propensity score matched cohort. BMC Musculoskelet Disord 19(1):236

25. Galea MP, Levinger P, Lythgo N, Cimoli C, Weller R, Tully E, Westh R (2008) A targeted home- and center-based exercise program for people after total hip replacement: a randomized clinical trial. Arch Phys Med Rehabil 89(8):1442-1447

26. Monaghan B, Cunningham P, Harrington P, Hing W, Blake C, O'Dohertya D, Cusack T (2017) Randomised controlled trial to evaluate a physiotherapy-led functional exercise programme after total hip replacement. Physiotherapy 103(3):283-288

27. Maire J, Faillenet-Maire AF, Grange C, Dugué B, Tordi N, Parratte B, Rouillon JD (2004) A specific arm-interval exercise program could improve the health status and walking ability of elderly patients after total hip arthroplasty: a pilot study. J Rehabil Med 36(2):92-94

28. Maire J, Dugué B, Faillenet-Maire A, Smolander J, Tordi N, Parratte B, Rouillon J (2006) Influence of a 6-week arm exercise program on walking ability and health status after hip arthroplasty: a 1-year follow-up pilot study. J Rehabil Res Dev 43(4):445

29. Giaquinto S, Ciotola E, Dall'Armi V, Margutti F (2010) Hydrotherapy after total hip arthroplasty: a follow-up study. Arch Gerontol Geriatr 50(1):92-95

30. Monticone M, Ambrosini E, Rocca B, Lorenzon C, Ferrante S, Zatti G (2014) Task-oriented exercises and early full weight-bearing contribute to improving disability after total hip replacement: a randomized controlled trial. Clin Rehabil 28(7):658-668
31. Umpierres A, Ribeiro TA, Marchisio AE, Galvao L, Borges K, de Souza Macedo CA, Galia CR (2014) Rehabilitation following total hip arthroplasty evaluation over short follow-up time: randomized clinical trial. J Rehabil Res Dev 51(10)

32. Beaupre LA, Masson EC, Luckhurst BJ, Arafah O, O'Connor GJ (2014) A randomized pilot study of a comprehensive postoperative exercise program compared with usual care following primary total hip arthroplasty in subjects less than 65 years of age: feasibility, selection of outcome measures and timing of assessment. BMC Musculoskelet Disord 15(1):192

33. Nankaku M, Ikeguchi R, Goto K, So K, Kuroda Y, Matsuda S (2016) Hip external rotator exercise contributes to improving physical functions in the early stage after total hip arthroplasty using an anterolateral approach: a randomized controlled trial. Disabil Rehabil 38(22):2178-2183

34. Mikkelsen LR, Mechlenburg I, Søballe K, Jørgensen LB, Mikkelsen S, Bandholm T, Petersen AK (2014) Effect of early supervised progressive resistance training compared to unsupervised home-based exercise after fast-track total hip replacement applied to patients with preoperative functional limitations. A single-blinded randomised controlled trial. Osteoarthr Cartil 22(12):2051-2058

35. Winther SB, Foss OA, Husby OS, Wik TS, Klaksvik J, Husby VS (2018) A randomized controlled trial on maximal strength training in 60 patients undergoing total hip arthroplasty: implementing maximal strength training into clinical practice. Acta Orthop 89(3):295-301

36. Trudelle-Jackson E, Smith SS (2004) Effects of a late-phase exercise program after total hip arthroplasty: a randomized controlled trial. Arch Phys Med Rehabil 85(7):1056-1062

37. Husby VS, Helgerud J, Bjørgen S, Husby OS, Benum P, Hoff J (2009) Early maximal strength training is an efficient treatment for patients operated with total hip arthroplasty. Arch Phys Med Rehabil 90(10):1658-1667

Publisher's Note Springer Nature remains neutral with regard to jurisdictional claims in published maps and institutional affiliations. 